\title{
Persuasive narrative during the COVID-19 pandemic: Norwegian Prime Minister Erna Solberg's posts on Facebook
}

\author{
Sanjana Arora (i] ${ }^{1 凶}$, Jonas Debesay ${ }^{2} \&$ Hande Eslen-Ziya (iD ${ }^{1}$
}

This article explores the Facebook posts of Norway's Prime Minister Erna Solberg to highlight the key features of her crisis communication during the COVID-19 pandemic. It draws on data from Solberg's Facebook posts from February 27, 2020 to February 9, 2021 (i.e., starting from the day when the first case of COVID-19 was recorded in Norway until the time of data collection for this study). Out of her 271 posts, 157 of them were about COVID-19 and were chosen for analysis. The analyses identified five major themes: (1) Promoting responsibility and togetherness (2) Coping (3) Being in control amidst uncertainty (4) Fostering hope and (5) Relating with the followers. Drawing inspiration from Boin, Stern and Sundelius', work on persuasive narratives, this study shows the ways that Solberg's posts about COVID-19 exhibit all five identified frame functions. In addition, the findings add contextual nuances to the frame functions through the theme of 'Responsibilization and togetherness', which are reflected through references to Norwegianness and the cultural concept and practice of dugnad. This study adds to our knowledge about how persuasive narratives are incorporated into the social media communication strategies of leaders and highlights the usefulness of this framework for studying ongoing and future crises.

\footnotetext{
${ }^{1}$ University of Stavanger, Stavanger, Norway. ${ }^{2}$ Oslo Metropolitan University, Oslo, Norway. ${ }^{凶}$ email: sanjana.arora@uis.no
} 


\section{Introduction}

he economic and social disruption caused by the COVID19 pandemic is having major impacts on people's livelihoods and their health. As of 18 April 2021, there have been 140,322,903 confirmed cases of SARS-CoV-2 infections and 3,003,794 deaths (WHO, 2021), making the COVID-19 pandemic an unprecedented global health crisis of the century. As countries across the world grapple with mitigating the risks associated with the pandemic, communication-an essential component of planning, response, and recovery during crisis (Houston et al., 2014) - has been one of the integral parts of the crisis management (Reddy and Gupta, 2020). Crisis communication highlights legitimation strategies, but also indicates how government institutions themselves make sense of crises (Brandt and Wörlein, 2020). Moreover, crises such as the COVID-19 pandemic can disrupt the socio-political order of societies, leaving a cognitive void in the minds of the public that can be filled with fear and uncertainty (Boin et al., 2016). In Norway, COVID-19 has been called a fear-driven pandemic that is based on alarming information of long-term illness and disability that is out of politicians control (Vogt and Pahle, 2020). Having control over the dramaturgy of political communication is thus central to effective leadership and crisis management (Boin et al., 2016). Effective communication can help societies handle uncertainty and promote adherence to behaviour change while fostering hope among the citizens (Finset et al., 2020).

The COVID-19 pandemic continues to rapidly evolve, and social media plays a pivotal role in meeting the communication needs of the public during such crisis (Van Dijck, 2013). As social media use increases during crises, leaders and public officials may utilise this platform to communicate, which in return helps reduce public panic and builds trust (Kavanaugh et al., 2012). As a result of the cultural and symbolic value of social media in contemporary times (Jenzen et al., 2021), the communication of public leaders in the midst of uncertainty and fear facilitates interpersonal and group interaction. Research has shown that, when compared to the traditional media platforms, social media platforms are used by leaders and elected officials to communicate, inform, and engage with their citizens (Golbeck et al., 2010). They use social media to spread messages farther and faster than it would be possible with traditional media (Sutton et al., 2013). What leaders post on social media can give insights into their communication and leadership strategies during crises. Understanding how leaders communicate with the public during crises will not only provide us with the knowledge about their governance styles but will also guide us to their meaning-making in times of uncertainty. Based on this assumption we will be studying the Facebook posts of Norwegian Prime Minister Erna Solberg, with the aim to highlight the key features of her communication. In doing so, we will take an exploratory rather than confirmatory perspective (Boudreau et al., 2001).

Solberg, member of the Conservative Party and in power since 2013, was defeated by the centre-left as this paper was being revised. Solberg has had a long career in politics, becoming a deputy representative to the Bergen City Council in 1979 when she was 18 years old. She was elected to the Parliament in 1989 where she was the youngest member of her party group (Notaker and Tvedt, 2021). Solberg's tough stance on issues such as immigration earned her the nickname of 'Jern-Erna' [Iron Erna] (Reuters, 2013). However, upon her appointment as Prime Minister, Solberg displayed a 'softer side' by caring about voters' jobs, health, and schools (Notaker and Tvedt, 2021).

The first Norwegian COVID-19 patient was diagnosed on February 26, 2020. While the initial spread of infection was relatively slow, cases increased quickly by March $12^{\text {th }}$, after winter break for schools ended and many Norwegians returned from skiing holidays in Northern Italy (Dagsavisen, 2020). On March 12 , the Norwegian Directorate of Health (NDH) adopted comprehensive measures to prevent the spread, which included closing day care centres, schools, and educational institutions. The measures also included a ban on cultural events, closed swimming gyms and pools, a halt to all service provisions that involved being less than one meter away from another person, and prohibiting visits to recreational cabins ${ }^{1}$, among others. Behavioural measures such as recommendations to keep physical distance, encourage handwashing, quarantine, stay home when ill, work from home, and avoid public transportation were also included. Following the lockdown, Norway became the first European country to announce that the situation was under control due to low levels of hospitalizations and mortalities (Christensen and Lægreid, 2020). In Norway, as of March 22, 2021, there have been over eighty thousand confirmed cases of coronavirus infection and more than six hundred deaths due to COVID-19. Norway has had far fewer COVID-19 cases, deaths, and hospitalizations per capita than most other countries in Western Europe or the United States (Christensen and Lægreid, 2020). Compared to its Scandinavian neighbours Denmark and Sweden, the proportion of cases of infections and deaths have been much lower (WHO, 2021), despite the three countries sharing similar social welfare and healthcare systems. Recently, a report submitted by the Corona Committee in Norway also concluded that the overall handling of the crisis by the government has been good. Not only has the number of infections and deaths in Norway been much lower than most countries in Europe, but the healthcare services have also remained stable, and society has remained relatively open (Lund, 2021). It is probable that good governance and responsible leadership demonstrated by the Norwegian cabinet and Prime Minister Erna Solberg contributed to this success.

In Norway, there is considerably less focus on individualization of candidates in political parties as compared to for instance the US, since the electoral system in Norway is based on proportional representation (Karlsen and Enjolras, 2016). Despite this, with the presence of digital and social media, there has been increasing focus on the individual candidates, leading to 'decentralising personalisation' (Karlsen and Enjolras, 2016; Balmas et al., 2014). Given this context, Erna Solberg's Facebook account during the COVID-19 pandemic serves as an intermediary platform between the government's role and her own personal profile as the Prime Minister who has been handling the COVID-19 crisis. Solberg has used Facebook more actively than other outlets like Twitter and has more followers on Facebook than any other platform. The proportion of Facebook users in Norway vis-a-vis other social media platform is also the highest (for example, $84 \%$ of people use Facebook compared to $22 \%$ who use Twitter who use Twitter) (Werliin and Kokholm, 2016). Facebook thus serves as an important platform for public leaders in Norway during crises, and therefore, by analysing Solberg's Facebook posts, we aim to demonstrate the key features of her communication strategy during the COVID-19 crisis.

\section{Background on crisis and crisis communication}

Crisis is defined as a rare, and significant public situation creating undesirable consequences (Coombs, 2015; Gruber et al., 2015). In most cases it is 'an unpredictable event that threatens important expectancies of stakeholders and can seriously impact an organization's performance and generate negative outcomes' (Coombs, 2015: p. 3). Crisis communication on the other hand is referred as the strategies used to lessen the uncertainties during crisis via the dissemination and exchange of information (Collins et al., 2016). 


\section{Table 1 List of variables scrutinised in the analysis.}

Date

Nature of the period of the post

Nature of the post

Number of interactions

Number and type of reactions

Description of the content of the post
Date when the post was made

During any critical period (such as before, during or after key measures introduced)

$1=$ Providing information about new measures/COVID related developments, initiatives $2=$ Reminding/asking

to continue following measures, $3=$ Holiday greetings, $4=$ Praising/thanking healthcare workers or other

members of society $5=$ Press conference $8=$ Other

The total number of reactions, shares and comments on a Facebook post

Instances where a user reacts to a post with a like, heart, sad, angry, laughing, surprise and care emoji

Summary of the notable features of the post
Effective crisis communication establishes reliability and maintains public trust. It should be frequent, consistent and involve compassionate messages conveyed in an inspired and transformational communication style. It is essential that public officials and leaders when communicating crisis relevant information be efficient and informative. Past research has shown the importance of repetition of the consistent interaction to help the message reach the recipients clearly and increase compliance behaviour in cases of crisis (Stephens et al., 2013). Inconsistent messages on the other hand were found to cause misperception and confusion, leading to a non-compliant behaviour by the recipients. The content of the message as well as its tone is also an important indicator of whether the recipients will comply or not (Sutton et al., 2013). Sources of crisis communication, such as leaders and public health officials, are perceived to be reliable and trustworthy when they exhibit concern and care (Heath and O' Hair, 2010). In addition, they can be more effective in building relationship with the public, if they consider the cultural factors that play a role in their communicating about risks (Aldoory, 2010).

Boin et al. (2016) argue that crisis communication is one of the key challenges, which leaders face during a crisis situation. During crisis communication, leaders are required to frame 'meaning' of the crisis in order to shape how public perceives the risks, consequences and how they respond to the measures being taken. Developing a persuasive narrative in communication is thus integral to succesful framing of the crisis and for a strategic leadership. The construction of a successful persuasive narrative requires five frame functions: namely that the narrative will offer a credible explanation of what happened, it will provide guidance, instil hope, show empathy, and suggest that leaders are in control (Boin et al., 2016). In doing so, leaders aid the public's understanding of the facts associated with crisis while sumltaneously acknolwedging and appealing to collective emotions. In incorporating these frame functions, leaders are posed with various choices and decision-making such as how they choose to or not choose to dramatise the situation, the language that they use and how they appeal to the colleactive emotions and stress.

As digital media technologies became popular resources for getting and spreading information, public officials and leaders also increasingly started using them as domains during the crises. In fact, for some scholars the use of social media while enabling mutual interaction between the leaders and recipients has altered the field of crisis communication altogether. For instance, it was found that as social media enables constant and effective communication, it was used more regularly than traditional media outlets during crisis (Kim and Liu, 2012). Similarly, Utz et al. (2013) discussed how for effective crisis communication strategy, the use of media channels, social media-Twitter, and Facebookversus traditional- newspapers-was more critical than the type of the crisis. Moreover, Schultz et al. (2011) concluded that when compared to traditional media networks, crisis communication received less negative response when social media was used. Hence, it is not to our surprise that public officials nowadays are turning to social media platforms for communicating with the masses during crisis. They not only use these tools to communicate about crisis but also request information from the public. This was the case during the COVID-19 pandemic crisis where social media was employed by political leaders across the globe to mediate the communication of information about the pandemic as well as for reaching out to their citizens. This paper by focusing on the Norwegian case and more specifically on the Norwegian Prime Minister's Facebook use during the time of COVID-19 pandemic aims to explore the use of social media platforms by political leaders during crisis. Our goal is to better understand how political leaders adapt social media technologies in their communication strategies during crises.

\section{Methods}

Our data that covers Erna Solberg's Facebook posts between February 27, 2020, and February 10, 2021 (a total of 271 posts) were extracted from ${ }^{2}$ into an Excel sheet. A total of 114 posts were removed as they were not related to COVID-19 leaving us 157 posts for further analysis. To aid the coding process, we noted the variables presented in Table 1 . These are: date, number of interactions, number, and type of reactions (e.g., angry, sad, like, etc.), URLs of links shared, and a description of the content of the posts that was later used in the qualitative analysis. We also noted if the posts were made during any particularly critical period (e.g., before, during or after new restrictive measures were introduced). The content of the posts and the number of likes and other reactions derived from this data should be considered a 'snapshot' of Solberg's posts as they appeared at the time of data collection (Brügger, 2013), as it is possible that some posts have been subsequently removed, or that the numbers and types of reactions to the posts have changed by the publication date

The data was analysed through thematic analysis (Braun and Clarke, 2006): in the first step, we read all posts and generated the first set of codes. Next, we combined all the similar codes while labelling them in clusters and organised them into analytical themes/categories (see Fig. 1). The authors then discussed and reviewed these analytical themes and merged them into aggregate/conceptual themes. Lastly, we reviewed the aggregate themes through the lens of the five frame functions of persuasive narrative and identified commonalities and differences. We have included some posts under each theme to illustrate our analytical process and illuminate the themes (Sandelowski, 1994). All posts presented here were translated from Norwegian to English by the authors.

\section{Findings}

Our analysis resulted in five themes: (1) Promoting responsibility and togetherness (2) Coping (3) Being in control amidst uncertainty (4) Fostering hope and (5) Relating with the followers. In reviewing our findings from the framework of Boin et al. (2016), we found that all five frame functions of persuasive narrative were embedded in Solberg's posts and aligned with our themes. Below we discuss our themes with reference to frame functions of Boin 


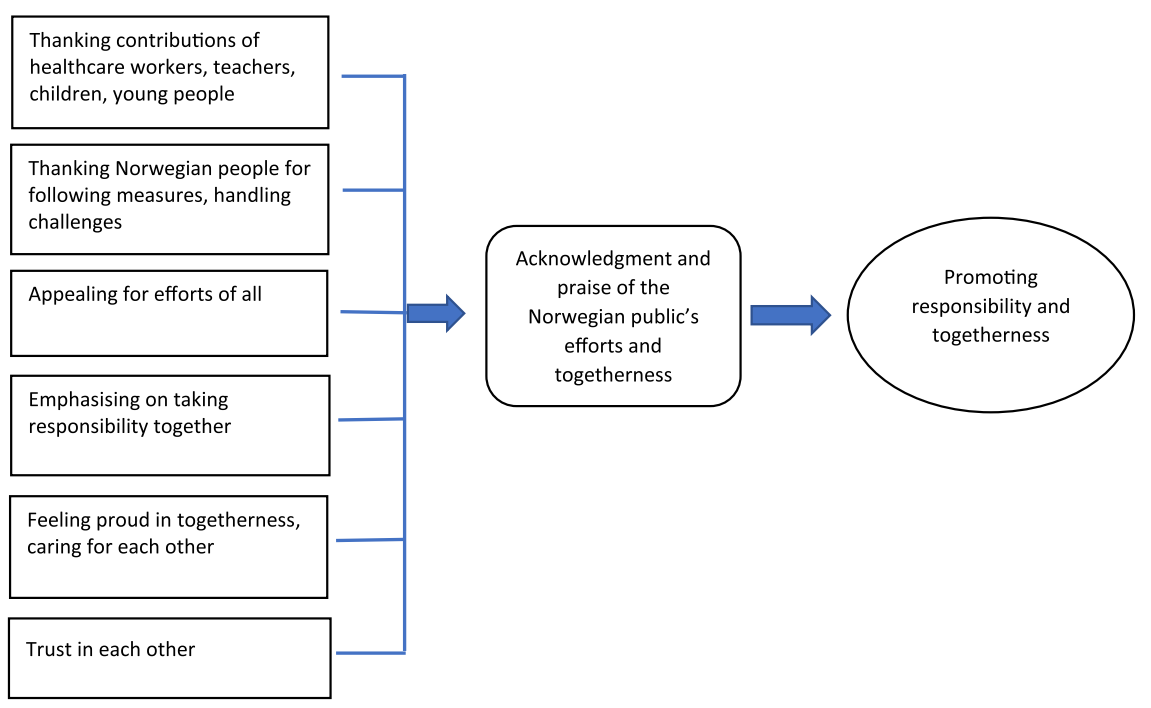

Fig. 1 Schematic formulation of a theme from the categories captured in posts.

et al. (2016) for a persuasive narrative and in doing so, add contextual nuances to each theme.

Promoting responsibility and togetherness: we are in this together. Analysis of Solberg's posts revealed a strong message of responsibility and togetherness. In almost all shares, she not only emphasized solidarity but also called for courage and responsibility. This Facebook post, shared soon after comprehensive shutdown measures were introduced, shows how important, for Solberg, was Norwegian solidarity expressed as 'we' (March 12, 2020):

Dear everyone. In times of crisis, we understand how dependent we are on each other. What unites us is more important than what separates us. This is not the time for

' $\mathrm{I}$ '. This is the time for 'we'.

Lunn et al. (2020) note that citizens are isolated during government induced or self-imposed quarantines: appeals to collective action and a spirit of 'we-are-in-it-together' are important ways to ensure compliance with quarantine and hence curb the rate of infection. Leaders in countries such New Zealand, UK, Brazil have also been found to have used a similar narrative emphasizing patriotic duty, love of country, and coming together as one, to mobilise community action (Dada et al., 2021).

Her posts were also imbued with appreciation and expression of gratitude towards healthcare workers and those who follow rules. For example, after introduction of the ban to travel to cabins and after the government's decision to extend regulations until after Easter, Solberg posted the following on April 4, 2020, receiving a high number of likes:

I feel proud when I see how we handle this together. Many thanks to everyone who follows the advice from the health authorities. Many thanks to everyone in the health service who works hard and perseveres. Many thanks to all Norwegians for the patience, love and solidarity we now show each other

The use of the word ' $\mathrm{I}$ ' and how it was being used in reference to 'feel[ing] proud', we argue, highlights the 'positioning of self by Solberg. Davies and Harré (1990) claim that development of the notion of 'positioning' is a contribution to the understanding of personhood, and how speakers choose to position their personal identity vis-a-vis their discontinuous personal diversity (such as being the Prime Minister, politician, Norwegian citizen, etc.). In such posts, whether intentionally or unintentionally, we also see the discursive practices through which Solberg allocates meaning to her position as a Prime Minister by emphasising that she feels proud upon seeing those who follow advice. At the same time, her emphasis on 'we', as in how 'we handle this together', places her as a member of the Norwegian masses.

Moreover, such references to togetherness and solidarity also reflect attempts to utilise the existing nationalistic cultural repertoire of the Norwegian concept of dugnad. For example, on New Year's Day following the Gjerdrum community disaster (a sudden and unexpected mudslide that destroyed several residential houses) and rise in the number of infections during the holiday period (2125 reported cases on December 29, 2020), Solberg posted the following post:

[...] During the year we have put behind us, Norway has lined up for the big dugnad. People have put their interests and dreams on hold to protect the elderly and the risk groups. It has saved lives. I am deeply grateful, proud and touched, for the way the Norwegian people have handled the biggest challenge for our society since World War II. We lined up for each other when it mattered most...

Dugnad in Norwegian is voluntary work that is performed as a collective effort (Moss and Sandbakken, 2021). Nilsen and Skarpenes (2020) discuss how the concept of dugnad is embedded in a moral repertoire of the socially responsible citizen that is indicative of a specifically Norwegian welfare mentality and conclude that dugnad is imperative for the sustainability and resilience of the Norwegian welfare model. Before the pandemic, Simon and Mobekk (2019) argued that the concept of dugnad is central to Norwegian culture, inculcating prosocial and cooperative behaviour, and thereby plays a role in Norway being one of the most egalitarian democracies and having high levels of equality and reciprocity. In the context of COVID-19, social anthropologist Thomas Hylland Eriksen (2020) pointed out that one reason for the success of the Norwegian approach was the mobilisation of broader society to fight COVID-19, driven by the notion of dugnad. Similarly, Moss and Sandbakken (2021) analysed data from press conferences and interviews with members of the public and found that many participants mentioned liking how the government talked of 'a spirit of dugnad' (dugnadsand), appealing to shared voluntary work rather than strict rules. The authors posit that in a pandemic it is crucial to create and use meta-narratives that are a good fit with the 
context in order to aid meaning-making and increase compliance. The use of dugnad as a cultural repertoire has, however, met with criticism from some scholars, who argue that 'a word associated with solidarity, unity, and voluntary work obscures the forced nature of the measures' (Tjora, 2020) and shifts the onus for finding solutions onto individual citizens or groups (Nilsen and Skarpenes, 2020; Hungnes, 2016).

Despite the criticism of imbibing such cultural repertoire, the alignment of the key values of Norwegian society with the core message of encouraging collective action is essential for a crisis narrative to be politically effective (Boin et al., 2016). Furthermore, the theme of 'Promoting responsibility and togetherness' shows the context specific nature of crisis communication narrative in the case of COVID-19 in Norway and therefore adds to the components for a persuasive narrative.

Coping: everything will be fine. Solberg's ${ }^{3}$ posts also carried messages that address the consequences of coping with COVID19 , namely self-isolation, and loneliness. For instance, her posts guided followers in dealing with loneliness and maintaining general physical and mental health. The Norwegian government, like that of many other countries, had introduced measures such as mandatory quarantine and social distancing rules to manage the spread of the virus. Studies have shown that home confinement during COVID-19 has negatively affected the emotional state of individuals due to depression and anxiety and has led to or increased a sedentary lifestyle (Sang et al., 2020). Thus, emphasis on the well-being of the population during COVID-19 is important for effective crisis management (WHO, 2020a) because increased well-being would reinforce its coping abilities during illness and hardships. As these are not the direct effects of the COVID-19 infection, but a result of the contagion containment measures imposed on citizens by the government, we observe Solberg taking responsibility and providing solutions to help. In doing so, she appears sensitive and caring towards the public.

Christensen and Lægreid (2020) attribute the 'high-performing' handling of the pandemic in Norway to the initial focus on suppression, followed by a control strategy. The authors further examine the ideas that having successful communication with the public, a collaborative and pragmatic decision-making style, the country's resourcefulness, and high trust of government all contributed to the relative success in Norway. Adopting the correct and effective strategy indeed heavily influences the outcomes of crises. However, to fill the 'cognitive void' that the public might be experiencing, leaders need to manage the meaning-making process and ensure legitimacy of their actions (Boin et al., 2016). Solberg and the other ministers played an important role in communicating with citizens and the media through daily media briefings together with the NDH (Norwegian Directorate of Health) and NIPH (Norwegian Institute of Public Health) (Christensen and Lægreid, 2020)

Solberg emphasized the impact of loneliness, for example, during one of the first holiday periods during the pandemic when comprehensive shut-down measures were introduced, she wrote:

Many people may feel lonely during holidays such as Easter, and the corona crisis exacerbates this. Therefore, I would like to encourage everyone to call someone you know is alone at Easter. The little things can mean a lot. Happy Easter!

A study by Blix et al. (2021) on the topic of mental health in the Norwegian population during the COVID-19 pandemic found that a substantial proportion of the population experienced significant psychological distress in the early phases. More than one out of four reported ongoing psychological distress over the threshold for clinically significant symptoms. Two other categories of individuals (those recently exposed to violence and those with pre-existing mental health problems) were found to be at special risk but worrying about the consequences of the pandemic was also found to contribute negatively to mental health. In this regard, Shah et al. (2020) argued that several nations have failed to address the mental health aspect among the public, as far more effort is being focused on understanding the epidemiology, clinical features, transmission patterns, and management of COVID-19. Solberg's open discussion about mental health during the pandemic implies a situation-specific and data-driven strategy of managing the less visible effects of the pandemic and show insight in anticipating future needs (Han et al., 2020).

Moreover, Solberg's posts also subtly utilised the Norwegian concept of friluftsliv, which translates as 'free air life,' a philosophy of outdoor living and connection with nature (Henderson and Vikander 2007). Friluftsliv is associated with grand narratives of Norwegian national identity depicting outdoor adventures, foraging, and a deep connection to nature (Jørgensen-Vitters $ø, 2021$ ). For example, with the re-opening of DNT [Den Norske Turistforening] cabins in mid-2020, Solberg in her post on June 11 emphasized the importance of being outdoors in fresh air:

We need to use our bodies and get out into the light and fresh air. It is important for both physical and mental health! I hope many have a good and active Norwegian holiday this year!

In these posts, Solberg also shared pictures of herself being outdoors. In such ways, Solberg appeared to be offering not only guidance for coping with the challenges and consequences of living during the pandemic, but also emphasizing one characteristic of the Norwegian culture, which they are proud ofspending time in nature. Be it advice to spend time in nature, or to keep social distance or self-isolation, we consider that Solberg's approach to coping aligns with the frame function of 'offering guidance'. During a crisis, leaders have a window of opportunity during which they can communicate a frame to not only make sense of the crisis but also to provide guidance and to portray themselves as attentive and concerned about the challenging circumstances faced by the public (Boin et al., 2016). By depicting herself as attuned to the emotions experienced by her followers during the pandemic and by utilising the moment to suggest ways of coping, Solberg's communication encapsulates the frame function of offering guidance for a persuasive narrative.

Being in control amidst uncertainty. In her posts, Solberg presented a narrative of being in control amidst uncertainty, which aligns with two of the frame functions of Boin et al. (2016), namely offering a credible explanation and suggesting that leaders are in control. In times of a crisis, it is important that leaders do not downplay the gravity of the situation or claim unrealistically optimistic scenarios (Boin et al., 2016). We see that Solberg maintained a balance by providing a detailed explanation of her actions and the reasons behind the restrictive measures taken. At the same time, she acknowledged the uncertainty inherent in the ever-changing crisis and demonstrated her concern. According to Lunn et al. (2020), in situations characterised by uncertainty and fear, responsible leaders need to signal that they are in control of the situation, which can be demonstrated by making decisions with confidence and honesty. Moreover, it is also essential that leaders do not make promises that are impossible or unrealistic, because doing that can impede the persuasiveness of their narrative by affecting their credibility later (Boin et al., 2016). 
In Solberg's posts, we see that she displays confidence but also the reality of uncertainty and concern, which is a sign of effective leadership and shows 'bounded optimism' (Brassey and Kruyt, 2020). The following post where she writes about her worries and concerns followed by advice is a good example of credibility and control:

I am worried. Right now, we have ongoing outbreaks in Bergen, Oslo, Trondheim and Hammerfest... We know that vigorous work is being done intensively in these municipalities with infection detection and other measures. Although Norway has relatively low infection rates, we also register here at home that the number of hospital admissions and the number of infected have increased recently. We now have the highest number of hospitalized patients with COVID-19 since May... We also see that the infection has begun to spread to older age groups. And there is a significant risk that the numbers will continue to rise as we see in Europe. That is why we have today announced new national austerity measures next week. We can still reverse the trend here at home...

A demonstration of concern from role models has been shown to have a role in persuading the public to adhere to recommendations (Simon and Mobekk, 2019). Tannenbaum et al. (2015) note that fear is easier to handle when it is acknowledged, which relates to the idea of 'citizens being anxious enough to take the advice from the authorities to heart and optimistic enough as to feel that their actions make a difference' (Petersen, 2020). Inculcating 'optimistic anxiety' (Tannenbaum et al., 2015) is therefore an important feature of crisis communication narratives.

Another important nuance that emerges from Solberg's posts is her comparisons to other countries to draw attention to the seriousness of the situation. For example, on November 5, 2020, Solberg made the following post announcing new national measures, which received over 5000 likes:

My message to the Norwegian people is: Stay at home as much as possible. Have the least possible social contact with others. It is absolutely necessary to avoid a new shutdown. Norway is at the beginning of the second wave of infection... The virus is spreading rapidly and all counties now have outbreaks. The government is therefore introducing new national infection control measures... If the current rate of infection continues, the number of inpatients in intensive care units will increase sharply in the coming weeks. This will lead to less intensive capacity for other seriously ill people. We are now where the Netherlands was at the beginning of September. A very rapid increase in infection in the Netherlands quickly led to more patients in the intensive care unit... Other European countries have similar experiences. There is therefore a heavy seriousness about the situation. And we must take responsibility together

By giving detailed reasoning behind measures being taken amidst uncertainty, Solberg exhibits both confidence and honesty in her narratives (Lunn et al., 2020). Another key feature that emerges from the post above is the emphasis on the risks of an increase in infection, and the possibility of a new lockdown and overburdening of intensive care capacity, thereby reflecting a more strongly persuasive intent. Such emphasis on the risks is different from other posts where Solberg exhibits control and optimism much more strongly. This adaption from a communicative stance to a more persuasive one could result from not only the perceived severity of the situation, but also the perceived risks of pandemic fatigue. Pandemic fatigue has been defined by the $\mathrm{WHO}$ as a lack of motivation to adhere to recommended protective behaviours (WHO, 2020b). According to surveys conducted in different countries, most people have been shown to possess adequate knowledge of COVID-19 and the precautions required to keep safe, yet factors like emotions and context have been found to have greater impact on behaviours than knowledge (Gavi the Vaccine Alliance, 2020). A study of different ways of communicating healthcare messages suggested that believability of the messages and the recipients' reactions to them can be influenced by the persuasive intent (Wang and Shen, 2019). Koh et al. (2020) also discuss the importance of devising effective and successful communications for a sustained period without message fatigue setting in, which includes concern for the way the communication is framed. Overall, we see that Solberg's posts provide a rationale with portrayal of the government being in control of managing the crisis.

Fostering hope and return to normalcy. Solberg's posts also emphasized the hopeful aspects of the crisis by appealing to followers to look forward to a return to everyday life, and new educational and economic prospects, despite the difficult current circumstances. This theme aligns with the frame of 'instilling hope' as per frame functions for a persuasive narrative by Boin et al. (2016). During a crisis, more than ever, effective leaders embody the hopes and fears of the society under threat, and therefore they should strive to inculcate optimism of a better future (Boin et al., 2016). Previous research has documented that in times of turmoil, followers especially look up to leadership that serves as a beacon of hope for and faith in a positive future, more than they do in times of prosperity (Stam et al., 2018; Shamir et al., 1993). According to Boin et al., leadership during crisis always has a moral dimension. On January 10, 2021, by which time Norway had witnessed over 50000 cases of infection and over 400 deaths as well as the Gjerdrum disaster, Solberg made the following post:

Dear everyone. This year I hope we can take our dreams back. After a year of pandemic and fear. Then I look forward to seeing creativity unleashed...

Another post that emphasized the optimism for educational prospects was made on April 15, 2020, and drew over 5000 likes:

Today is the last deadline to apply to a vocational school, college or university. I understand that it can feel strange to apply for an education this autumn while the educational institutions keep their campuses closed. Maybe someone also thinks the idea of moving from home to a new city seems extra scary these days. To you I want to say that everyday life will return. Therefore, my appeal to you who want to study: do not put your life on hold, but apply for education this year!

Lessons from previous crises tell us that leaders need to pay attention to the fear of the ongoing threat, as well as sadness and grief, and to provide hope to mitigate social disruption (Maak et al., 2021). Here, we see that Solberg's is attempting to convey hope while also acknowledging the challenges and impact of COVID-19. In doing so, the messages also emphasise self-efficacy and trust in the government. Hope and resilience are closely aligned constructs, as they both include a tendency towards maintaining an optimistic outlook in the face of adversity (Duggal et al., 2016). Thus, fostering hope during crisis can help the community cope with the consequences of the crisis. Moreover, by using emotional appeals, leaders can influence attitudes and behaviours as well as induce compassion (Ghio et al., 2020).

The theme of fostering hope in Solberg's posts was found to be particularly emphasized during and before national holidays or important events. Her posts often utilised humour to foster 
positivity, particularly during critical periods such as during or after implementation of stricter COVID-19 measures. For example, a day after it was announced that infection-reduction measures would continue throughout Christmas, Solberg shared a snipped of her response to a question asked in a press conference and posted:

Can Santa actually come to visit this year?

Creating human moments and hope is a sign of compassionate leadership and helps to establish the relational foundation for widespread support for pandemic control measures (Maak et al., 2021). Also, by utilising humour, Solberg adapts the tone of her messages, a tactic that has been found to significantly affect audiences' attitudes and behaviours, help people manage their emotions, and strengthen support for pandemic measures (Lee and Basnyat, 2013)

Relating with followers. The last theme is about the posts in which Solberg relates to the public by providing personal information, acknowledging, and relating with the difficult circumstances, and using humour or a private tone in her posts. For example, the post below was made just before Easter and it received more than 13000 likes, making it to be the third-most liked post of Solberg related to COVID-19 during this period.

It will be a different Easter this year. Let's make the best of it. We can play fun board games with our loved ones, read the book we never have time to read, listen to an audiobook or explore the local area. The last few weeks have been challenging for all of us, but we want to get through this...

Sindre and I have recharged with board games and wish you all a very happy Easter!

Empathy is an important component of the persuasive narrative, especially during crises when the decisions made by authorities to mitigate, and control can also have consequences for people's lives. For crisis communication to be effective, the information provided to the public should not be too factual or portray leaders as distant from the citizens (Shen, 2010; Lunn et al., 2020). By demonstrating concern and acknowledging the impact of crises, leaders can empathise with the public (Shen, 2010; Lunn et al., 2020). We see Solberg personifying the challenges of COVID-19 by referring to how the times have been challenging for 'all of us'. According to Boin et al. (2016), a leader's personification of suffering is instrumental in showing empathy because the public is then able to relate to them.

Further, previously in a study by Larsson (2015) about Norwegian party leaders on Facebook during the 2013 'short campaign', it was found that personal content referencing private life is increasingly employed by Norwegian party leaders. Enli and Rosenberg (2018) investigated voters' evaluations of politicians as authentic or 'real,' and Solberg was found to be one of the most perceived authentic politicians. Enli (2014) had earlier suggested that Erna Solberg's public profile as predictable, anti-elitist and imperfect constructs her authenticity.

A similar example of relatability with followers during the pandemic was the instance when she forgot the rule of not shaking hands during public meetups and press conferences. After the event, she wrote:

It is important that we can have some humour in a difficult time (-) Even a prime minister can forget, but now it is important that we all remember to follow the advice of the health authorities..

She also used an engaging communicative style when interacting with her followers:

Then the holiday is over... a different summer, a little cold, weekly meetings in the Government's Corona Committee on video, beautiful nature experiences from Norway and a lot of rain. Let me share a wonderful little meeting with a lynx on the lawn on Varaldsøy... Have you had a nice summer?

Thus, Solberg embeds references to her private life, which also helps to personify the messages in her posts and thus relate with the public. In addition, by relating with the public on an everyday basis and through the acknowledgment of shared challenges during crisis, Solberg's narrative also appears empathetic. Our theme of 'Relating to the public' thus encapsulates frame function of 'showing empathy' for developing a persuasive narrative, as per Boin et al. (2016).

\section{Concluding remarks}

This paper was an attempt to explore the Facebook posts of Norway's Prime Minister Erna Solberg to highlight the key features of her crisis communication during the COVID-19 pandemic. By drawing on data from Solberg's Facebook posts during the pandemic our analyses identified five major themes, (1) Promoting responsibility and togetherness (2) Coping (3) Being in control amidst uncertainty (4) Fostering hope and (5) Relating with the followers, where we went in detail explanation by using frame functions of a persuasive narrative by Boin et al. (2016). We furthermore discussed the specific Norwegian contextual nuances to the frame functions. These were the theme 'Responsibilization and togetherness', presented via the references to Norwegianness and the cultural concept and practice of dugnad. Hence, our paper showed how during crisis persuasive narratives are incorporated into the social media communication strategies of political leaders.

The paper also showed how persuasive narratives are delivered through praising the public's efforts, promoting togetherness, caring about the public's well-being, displaying optimism and confidence in the government's measures. It elaborated on how crisis management on social media was done via the use of humour and personal information. Humour was used as a tool to engage with the public and help them relate and comply to the COVID-19 restrictions. Hence, Solberg used Facebook to capitalise on a wide-reaching social medium (Hallahan, 2010). While the communication of leaders during crises helps to fill the cognitive void, the use of social media helps build societal resilience by improving awareness and encouraging preparedness (Boin et al., 2016)

Even so, the success of a persuasive narrative is to a great extent dependant on the credibility of its proponents (Boin et al., 2016). The reputation of the leader and the organisation that they represent plays a key role in framing a successful persuasive narrative. In general, Norwegians have more trust in each other and their institutions than most other countries (Skirbekk and Grimen, 2012). A survey conducted by the Norwegian Citizen's Panel [Norsk Medborgerpanel] in March 2020 found that trust in government, in the health authorities, in parliament, and in national and local politicians had increased, as did trust in the Prime Minister during the pandemic (Dahl, 2020). Clearly, Solberg seems to have benefitted from the trust capital in Norwegian society with her Facebook communications during a crisis. More recently, Erna Solberg has received heavy criticism for breach of COVID-19 restrictions during a family trip to Geilo for her 60th birthday (The Guardian, 2021a). Following which, Erna Solberg, has been investigated by police and fined (The Guardian, 2021b). Thus, while her Facebook posts exhibiting components of a persuasive narrative received popularity, her actions have nevertheless been subjected to scrutiny and criticisms in mainstream media (Larsen, 2021). According to Boin et al. (2016: p. 72), the retainment of confidence of the public is essential for the communication strategies to be effective. Therefore, such media 
criticism might undermine the credibility of Solberg and her cabinet, leading to less credible and politically ineffective narratives. On the other hand, past performances, and reputation also play an important role in increasing leaders' personal credibility in the face of crisis (Boin et al., 2016). Consequently, Solberg's long career in politics and her reputation of caring about the citizens as previously discussed, could buffer the recent impact on her credibility. Moreover, communication during and after a crisis affects long-term impressions (Coombs, 2007). With the personification of politics in Norway or 'decentralising personalization' (Balmas et al., 2014), the criticisms paved at Erna, however, reflect more of a personal crisis than a national crisis. And while we do not analyse Solberg's posts beyond $9^{\text {th }}$ Feb. 2021 i.e., after Solberg spoke about the Geilo trip incident on her Facebook account, we see that she follows similar strategy in handling this personal crisis as the national crisis of COVID-19, through use of a persuasive narrative. Future studies can therefore focus on how Solberg and other political leaders utilise the strategy of persuasive narrative in management of personal crisis in nexus with national crisis such as that of COVID-19.

Further, we concur with Christensen and Lægreid (2020) who write that the 'political leadership has succeeded well in connecting governance capacity and legitimacy using the argument that Norway had sufficient resources to deal with the crisis. While the health resource capacity and preparedness of Norway inarguably contributes to the outcomes of the crisis, communicating a successful persuasive narrative with credibility is integral to gaining legitimacy and filling the cognitive void (Boin et al., 2016). Erna Solberg's use of persuasive narrative in Facebook posts, seems therefore to have been effective in the management of the COVID-19 pandemic, but her latest unfortunate incident goes to show how politicians' management of crises is tenuous and highly dependent on public trust.

Our study adds to the significance and knowledge of how persuasive narratives are incorporated into the communication strategy of leaders on a social media platform and highlights the usefulness of this framework for studies about ongoing and future crises. By using data from social media, our findings also add to the understanding of the increased personification of politics and how leaders utilise this personification to communicate government measures and engage with the public during a crisis. Future research can further explore how public leaders and health authorities' frame crises situations, actions, issues, and responsibility to dramatise and reinforce key ideas (Hallahan, 1999). Such insights can pave way for understanding public's shaping of risk perceptions and compliance to behavioural measures during crises such as the COVID-19 pandemic.

\section{Data availability}

The dataset analysed during the current study is available through the public profile of Erna Solberg on Facebook: https:// www.facebook.com/ernasolberg/. This dataset was derived from Crowd Tangle which can be accessed through request at https:// www.crowdtangle.com/.

Received: 12 October 2021; Accepted: 17 January 2022; Published online: 01 February 2022

\section{Notes}

1 Known as 'hyttetur', cabin trips are deeply rooted in Norwegian culture and way of life

2 Crowdtangle extracts both historical and current data of post contents and metadata such as the date the post was made, number of likes, other reactions and shares.
Information about how to access raw material included in this study can be found in the data availability statement at the end of the article.

3 'Everything will be fine' [Alt blir bra] was one of the campaigns that spread because of the COVID-19 crisis in Norway depicting pictures of a rainbow.

\section{References}

Aldoory L (2010) The ecological perspective and other ways to (re)consider cultural factors in risk communication. In: Heath R, O' Hair (eds) Handbook of risk and crisis communication. Routledge, New York, pp. 227-246

Balmas M, Rahat G, Sheafer T, Shenhav SR (2014) Two routes to personalized politics: Centralized and decentralized personalization. Party Polit 20(1):37-51. https://doi.org/10.1177/1354068811436037

Blix I, Birkeland MS, Thoresen S (2021) Worry and Mental Health in the COVID 19 Pandemic: Vulnerability Factors in the General Norwegian Population. https://doi.org/10.21203/rs.3.rs-192098/v1. Accessed 10 Jun 2021

Boin A, Stern E, Sundelius B (2016) The politics of crisis management: Public leadership under pressure. Cambridge University Press

Boudreau MC, Gefen D, Straub DW (2001) Validation in information systems research: a state-of-the-art assessment. MIS Quart 25(1):1. https://doi.org/ $10.2307 / 3250956$

Brandt P, Wörlein J (2020) Government crisis communication during the pandemic. https://www.sciencespo.fr/en/news/news/government-crisis-communicationsduring-the-pandemic/4862. Accessed 20 May 2021

Braun V, Clarke V (2006) Using thematic analysis in psychology. Qual Res Psychol 3(2):77-101. https://doi.org/10.1191/1478088706qp063oa

Brassey J, Kruyt M (2020) How to demonstrate calm and optimism in a crisis McKinsey \& Company, April. 2020. https://www.mckinsey.com/businessfunctions/organization/our-insights/how-to-demonstrate-calm-andoptimism-in-a-crisis. Accessed 27 May 2021

Brügger N (2013) Historical network analysis of the web. Soc Sci Comput Review 31(3):306-21. https://doi.org/10.1177/0894439312454267

Christensen T, Lægreid P (2020) Balancing governance capacity and legitimacy: how the Norwegian government handled the COVID-19 crisis as a high performer. Public Admin Rev 80(5):774-9. https://doi.org/10.1111/ puar. 13241

Collins M, Neville K, Hynes W, Madden M (2016) Communication in a disasterthe development of a crisis communication tool within the S-HELP project. J Decis Syst 25(1):160-170. https://doi.org/10.1080/12460125.2016.1187392

Coombs WT (2007) Protecting organization reputations during a crisis: the development and application of situational crisis communication theory. Corp Reput Rev 10(3):163-176. https://doi.org/10.1057/palgrave.crr.1550049

Coombs WT (2015) Ongoing crisis communication: planning, managing and responding. Sage, Thousand Oaks, CA

CrowdTangle (2021) CrowdTangle Team. Facebook, Menlo Park, California, United States. List ID: 15044042021

Dada S, Ashworth HC, Bewa MJ, Dhatt R (2021) Words matter: political and gender analysis of speeches made by heads of government during the COVID-19 pandemic. BMJ Global Health 6(1):e003910. https://doi.org/ $10.1101 / 2020.09 .10 .20187427$

Dagsavisen (2020) FHI: Norge ble varslet om koronasmitte fra Østerrike allerede 4 mars 2020 (Norway was notified of corona infection from Austria as early as 4 March 2020). https://www.dagsavisen.no/nyheter/innenriks/2020/10/30/ fhi-norge-ble-varslet-om-koronasmitte-fra-osterrike-allerede-4-mars/. Accessed on 1 Apr 2021

Dahl T (2020) Stolar meir på Erna og mindre på naboen (Rely more on Erna and less on the neighbor). https://www.uib.no/aktuelt/135017/stolar-meir-p\% C3\%A5-erna-og-mindre-p\%C3\%A5-naboen. Accessed 3 Jul 2021

Davies B, Harré R (1990) Positioning: the discursive production of selves. J Theory Soc Behav 20(1):43-63. https://doi.org/10.1111/j.1468-5914.1990.tb00174.x

Duggal D, Sacks-Zimmerman A, Liberta T (2016) The impact of hope and resilience on multiple factors in neurosurgical patients. Cureus $8(10)$. https:// doi.org/10.7759/cureus.849

Enli G (2014) Mediated authenticity. Peter Lang Incorporated, New York

Enli G, Rosenberg LT (2018) Trust in the age of social media: Populist politicians seem more authentic. Soc Media Soc 4(1):2056305118764430. https://doi.org/ $10.1177 / 2056305118764430$

Eriksen TH (2020) Norway's response to Covid-19 and the Janus face of Nordic trust. https://www.coronatimes.net/norway-covid-19-nordic-trust/. Accessed on 15 May 2021

Finset A, Bosworth H, Butow P, Gulbrandsen P, Hulsman RL, Pieterse AH et al. (2020) Effective health communication-a key factor in fighting the COVID19 pandemic. Patient Educ Couns 103(5):873. https://doi.org/10.1016/ j.pec.2020.03.027

Gavi the Vaccine Alliance (2020) 10 reasons why pandemic fatigue could threaten global health in 2021. https://www.gavi.org/vaccineswork/10-reasons-whypandemic-fatigue-could-threaten-global-health-2021. Accessed 15 Jun 2021

Ghio D, Lawes-Wickwar S, Tang M, Epton T, Howlett N, Jenkinson E (2020) What influences people's responses to public health messages for managing risks 
and preventing infectious diseases? A rapid systematic review of the evidence and recommendations. https://doi.org/10.31234/osf.io/nz7tr. Accessed 28 May 2021

Golbeck J, Grimes JM, Rogers A (2010) Twitter use by the US Congress. J Am Soc Inform Sci Technol 61(8):1612-21. https://doi.org/10.1002/asi.21344

Gruber DA, Smerek RE, Thomas-Hunt MC, James EH (2015) The real-time power of Twitter: Crisis management and leadership in an age of social media. Bus Horizon 58(2):163-172. https://doi.org/10.1016/j.bushor.2014.10.006

Hallahan K (1999) Seven models of framing: implications for public relations. J Public Relat Res 11(3):205-242. https://doi.org/10.1207/s1532754xjprr1103_02

Hallahan K (2010) Crises and risk in cyberspace. In: Heath R, Hair O' (ed) Handbook of risk and crisis communication. Routledge, New York, NY, pp. $412-445$

Han RH, Schmidt MN, Waits WM, Bell AK, Miller TL (2020) Planning for mental health needs during COVID-19. Curr Psychiatry Rep 22(12):1-10. https:// doi.org/10.1007/s11920-020-01189-6

Heath R, O' Hair H (2010) The significance of crisis and risk communication. In: Heath R, Hair O' (ed) Handbook of risk and crisis communication. Routledge, New York, pp. 5-30

Henderson B, Vikander N (eds) (2007) Nature first: outdoor life the friluftsliv way. Dundurn

Houston JB et al. (2014) Social media and disasters: a functional framework for social media use in disaster planning, response, and research. Disasters 39(1):1-22. https://doi.org/10.1111/disa.12092

Hungnes S (2016) Den norske dugnadskulturen (The Norwegian voluntary culture. https:/agendamagasin.no/kommentarer/den-norske-dugnadskulturen/. Accessed 25 May 2021

Jenzen O, Erhart I, Eslen-Ziya H, Korkut U, McGarry A (2021) The symbol of social media in contemporary protest: Twitter and the Gezi Park movement. Convergence 27(2):414-37. https://doi.org/10.1177/1354856520933747

Jørgensen-Vittersø KA (2021) From fresh air and sunbathing to wildlife and snow caves: 'Friluftsliv'in norwegian primary schools, 1939-1980. In: Roos M, Berge KL, Edgren $\mathrm{H}$ (eds) Exploring textbooks and cultural change in nordic education 1536-2020. Brill, pp 245-259

Karlsen R, Enjolras B (2016) Styles of social media campaigning and influence in a hybrid political communication system: linking candidate survey data with Twitter data. Inte J Press/Politics 21(3):338-57. https://doi.org/10.1177/ 1940161216645335

Kavanaugh AL, Fox EA, Sheetz SD, Yang S, Li LT, Shoemaker DJ et al. (2012) Social media use by government: from the routine to the critical. Gov Inform Q 29(4):480-91. https://doi.org/10.1145/2037556.2037574

Kim S, Liu BF (2012) Are all crises opportunities? A comparison of how corporate and government organizations responded to the 2009 flu pandemic. J Public Relat Res 24(1):69-85. https://doi.org/10.1080/1062726x.2012.626136

Koh PK-K, Chan LL, Tan E-K (2020) Messaging fatigue and desensitisation to information during pandemic. Arch Med Res 51(7):716-717. https://doi.org/ 10.1016/j.arcmed.2020.06.014

Larsen K (2021) Erna Solbergs popularitet stuper (Erna Solberg's popularity plummets). https://www.dagbladet.no/nyheter/erna-solbergs-popularitetstuper/73597485. Accessed 15th Apr

Larsson AO (2015) Pandering, protesting, engaging. Norwegian party leaders on Facebook during the 2013 'Short campaign'. Inform Commun Soc 18(4):459-73. https://doi.org/10.1080/1369118x.2014.967269

Lee ST, Basnyat I (2013) From press release to news: mapping the framing of the 2009 H1N1 A influenza pandemic. Health Commun 28(2):119-32. https:// doi.org/10.1080/10410236.2012.658550

Lund J (2021) Somling, rot og ulovligheter (Procrastination, clutter and illegalities). https://www.aftenposten.no/meninger/kommentar/i/BlPRjw/somling-rot-ogulovligheter. Accessed on 25 May 2021

Lunn P, Belton C, Lavin C, McGowan F, Timmons S, Robertson D (2020) Using behavioural science to help fight the coronavirus. J Behav Public Administration, 3(1). https://doi.org/10.30636/jbpa.31.147

Maak T, Pless NM, Wohlgezogen F (2021) The fault lines of leadership: Lessons from the global Covid-19 crisis. J Change Manag 21(1):66-86. https://doi.org/ $10.1080 / 14697017.2021 .1861724$

Moss SM, Sandbakken EM (2021) "Everybody needs to do their part, so we can get this under control." reactions to the norwegian government meta-narratives on COVID-19 measures. Polit Psychol 42(5):881-898. https://doi.org/ $10.1111 /$ pops. 12727

Notaker H, Tvedt KA (2021) Stor Norske Leksikon: Erna Solberg (https://snl.no/ Erna_Solberg. Accessed on 20 Apr 2021

Nilsen ACE, Skarpenes O (2020) Coping with COVID-19. Dugnad: a case of the moral premise of the Norwegian welfare state. International Journal of Sociology and Social Policy. (ahead-of-print). https://doi.org/10.1108/ijssp07-2020-0263

Petersen MB (2020) The unpleasant truth is the best protection against coronavirus. Politiken. https://pure.au.dk/portal/files/181464339/The_unpleasant_truth_is
_the_best_protection_against_coronavirus_Michael_Bang_Petersen.pdf. Accessed 11 Jun 2021

Reddy BV, Gupta A (2020) Importance of effective communication during COVID-19 infodemic. J Fam Med Prim Care 9(8):3793. https://doi.org/ 10.4103/jfmpc.jfmpc_719_20

Reuters (2013) Iron Erna's softer side wins through in Norway election 2013 https://www.scmp.com/news/world/article/1307898/iron-ernas-softer-sidewins-through-norway-election. Accessed 27 Apr 2021

Sandelowski M (1994) Focus on qualitative methods. The use of quotes in qualitative research. Res Nurs Health 17(6):479-482. https://doi.org/10.1002/ nur.4770170611

Sang X, Menhas R, Saqib ZA, Mahmood S, Weng Y, Khurshid S, et al. (2020) The psychological impacts of CoViD-19 home confinement and physical activity: a structural equation model analysis. Front Psychol 11. https://doi.org/ 10.3389/fpsyg.2020.614770

Schultz F, Utz S, Göritz A (2011) Is the medium the message? Perceptions of and reactions to crisis communication via twitter, blogs and traditional media. Public Relat Rev 37(1):20-27. https://doi.org/10.1016/j.pubrev.2010.12.001

Shah K, Kamrai D, Mekala H, Mann B, Desai K, Patel RS (2020) Focus on mental health during the coronavirus (COVID-19) pandemic: applying learnings from the past outbreaks. Cureus 12(3). https://doi.org/10.7759/cureus.7405

Shamir B, House RJ, Arthur MB (1993) The motivational effects of charismatic leadership: a self-concept based theory. Organ Sci 4(4):577-94. https:// doi.org/10.1287/orsc.4.4.577

Shen L (2010) Mitigating psychological reactance: the role of message-induced empathy in persuasion. Hum Commun Res 36(3):397-422. https://doi.org/ $10.1111 / j .1468-2958.2010 .01381 . x$

Simon C, Mobekk H (2019) Dugnad: a fact and a narrative of Norwegian prosocial behavior. Perspect Behav Sci 42(4):815-34. https://doi.org/10.1007/s40614019-00227-w

Skirbekk H, Grimen H (2012) Tillit i Norge (Trust in Norway). Res Publica, Oslo

Stam D, van Knippenberg D, Wisse B, Nederveen Pieterse A (2018) Motivation in words: promotion-and prevention-oriented leader communication in times of crisis. J Manag 44(7):2859-87. https://doi.org/10.1177/0149206316654543

Stephens KK, Barrett AK, Mahometa MJ (2013) Organizational communication in emergencies: Using multiple channels and sources to combat noise and capture attention. Hum Commun Res 39(2):230-251. https://doi.org/ $10.1111 /$ hcre. 12002

Sutton J, Spiro E, Butts C, Fitzhugh S, Johnson B, Greczek M (2013) Tweeting the spill: Online informal communications, social networks, and conversational microstructures during the Deepwater Horizon oilspill. Int J Inform Syst Crisis Resp Manag 5(1):58-76. https://doi.org/10.4018/jiscrm.2013010104

Tannenbaum MB, Hepler J, Zimmerman RS, Saul L, Jacobs S, Wilson K et al. (2015) Appealing to fear: a meta-analysis of fear appeal effectiveness and theories. Psychol Bull 141(6):1178. https://doi.org/10.1037/a0039729

The Guardian (2021a) Norwegian PM Erna Solberg investigated for Covid rules breach. Available at: https://www.theguardian.com/world/2021/mar/19/ norwegian-pm-erna-solberg-investigated-for-covid-rules-breach. Accessed 25th Mar 2021

The Guardian (2021b) Norwegian PM fined after breaking Covid rules with birthday party. Available at: https://www.theguardian.com/world/2021/apr/ 09/norway-prime-minister-erna-solberg-fined-breaking-covid-rulesbirthday. Accessed 15th Mar 2021

Tjora A (2020) Tillitsfull dugnad eller instruert solidaritet (Trusting voluntary work or instructed solidarity) https://www.universitetsavisa.no/koronavirus-ytring/ tillitsfull-dugnad-eller-instruert-solidaritet/111642. Accessed on 21 May 2021

Utz S, Schultz F, Glocka S (2013) Crisis communication online: How medium, crisis type and emotions affected public reactions in the Fukushima Daiichi nuclear disaster. Public Relat Rev 39(1):40-46. https://doi.org/10.1016/ j.pubrev.2012.09.010

Van Dijck J (2013) Facebook and the engineering of connectivity: A multi-layered approach to social media platforms. Convergence 19(2):141-55. https:// doi.org/10.1177/1354856512457548

Vogt H, Pahle A (2020) En fryktdrevet pandemi av varige helseproblemer (A feardriven pandemic of lasting health problems) https://www.aftenposten.no/ meninger/kronikk/i/opdB6a/en-fryktdrevet-pandemi-av-varige-helsepro blemer. Accessed 20 May 2021

Wang W, Shen F (2019) The effects of health narratives: Examining the moderating role of persuasive intent. Health Market Q 36(2):120-35. https:// doi.org/10.1080/07359683.2019.1575061

Werliin R, Kokholm M (2016) Device study: Social media across the Nordics. https://www.audienceproject.com/wp-content/uploads/study_social_media across_the_nordics.pdf. Accessed 18 Jun 2021

World Health Organization (2020a) Mental health and psychosocial considerations during the COVID-19 outbreak, 18 March 2020. https://www.who.int/docs/ default-source/coronaviruse/mental-health-considerations.pdf. Accessed 10 Jun 2021 
World Health Organization (2020b) Pandemic fatigue: reinvigorating the public to prevent COVID-19: policy framework for supporting pandemic prevention and management: revised version November 2020. World Health Organization. Regional Office for Europe. https:/apps.who.int/iris/handle/10665/ 337574. Accessed 17 Jun 2021

World Health Organization (2021) WHO Coronavirus (COVID-19) Dashboard 2021 https://covid19.who.int/?gclid=Cj0KCQjw9_mDBhCGARIsAN3PaFNVuA3kA BELXjY66cXUIVcTNNBkPrX57w1OtZL1GYBomSnvTRflQTcaAoxkEALw _wcB. Accessed 18 Apr 2021

\section{Acknowledgements}

This article is published as part of the research project 'Fighting Pandemics with Enhanced Risk Communication: Messages, Compliance and Vulnerability During the COVID-19 Outbreak (PAN-FIGHT)', which is financed by the Norwegian Research Council (Project number: 312767).

\section{Competing interests}

The authors declare no competing interests.

\section{Ethical approval}

This article does not contain any studies with human participants performed by any of the authors.

\section{Informed consent}

This article does not contain any studies with human participants performed by any of the authors.

\section{Additional information}

Correspondence and requests for materials should be addressed to Sanjana Arora.

Reprints and permission information is available at http://www.nature.com/reprints

Publisher's note Springer Nature remains neutral with regard to jurisdictional claims in published maps and institutional affiliations.

(c) (i) Open Access This article is licensed under a Creative Commons Attribution 4.0 International License, which permits use, sharing, adaptation, distribution and reproduction in any medium or format, as long as you give appropriate credit to the original author(s) and the source, provide a link to the Creative Commons license, and indicate if changes were made. The images or other third party material in this article are included in the article's Creative Commons license, unless indicated otherwise in a credit line to the material. If material is not included in the article's Creative Commons license and your intended use is not permitted by statutory regulation or exceeds the permitted use, you will need to obtain permission directly from the copyright holder. To view a copy of this license, visit http://creativecommons.org/ licenses/by/4.0/.

(C) The Author(s) 2022 